ANDRADE, Júlio Thalles de Oliveira. Os direitos fundamentais sociais à luz do princípio da vedação ao retrocesso social. Revista Eletrônica Direito e Política, Programa de Pós-Graduação Stricto Sensu em Ciência Jurídica da UNIVALI, Itajaí, v.11, n.1, $1^{\circ}$ quadrimestre de 2016. Disponível em: www.univali.br/direitoepolitica - ISSN 1980-7791.

\title{
OS DIREITOS FUNDAMENTAIS SOCIAIS À LUZ DO PRINCÍPIO DA VEDAÇÃO AO RETROCESSO SOCIAL
}

\author{
THE FUNDAMENTAL SOCIAL RIGHTS IN THE LIGHT OF THE PRINCIPLE OF \\ SEALING THE SOCIAL KICK
}

Júlio Thalles de Oliveira Andrade ${ }^{1}$

SUMÁRIO: Introdução; 1 Delimitação do Conceito de Princípios no Ordenamento Jurídico; 2 O Princípio da Vedação ao Retrocesso Social; 3 Reserva do Possível e Mínimo Existencial frente à Vedação ao Retrocesso Social; 4 O Princípio da Vedação ao Retrocesso na Ordem Constitucional Brasileira; 5 A Amplitude do Princípio da Vedação ao Retrocesso Social; Considerações Finais; Referências das Fontes Citadas.

\section{RESUMO}

O artigo discute o papel dos princípios no ordenamento jurídico nacional, em especial tratando acerca do princípio da vedação ao retrocesso social. Para isto, adota-se o entendimento de que os direitos sociais são direitos fundamentais, incitando a discussão dos fundamentos utilizados para se vedar a alteração ou exclusão de uma legislação infraconstitucional que implemente um direito social já consagrado. A ausência de critérios concretos e justificadores para limitar a efetivação dos direitos sociais pode levar a uma afronta ao princípio da vedação ao retrocesso social, desrespeitando-se, assim, o princípio da dignidade da pessoa humana. Para a elaboração do presente estudo, buscou-se subsídio na pesquisa bibliográfica, sendo adotado, para tanto, o método hipotético-dedutivo.

PALAVRAS-CHAVe: Direitos fundamentais. Direitos sociais. Princípio da vedação ao retrocesso social.

\footnotetext{
${ }^{1}$ Mestre em Direito Constitucional pela Universidade Federal do Rio Grande do Norte - UFRN. Especialista em Direitos Humanos pela Universidade do Estado do Rio Grande do Norte - UERN. Especialista em Direito Público pela Universidade Anhanguera - UNIDERP. Bacharel em Direito pela Universidade do Estado do Rio Grande do Norte - UERN. Servidor Público - Tribunal de Justiça do Estado do Rio Grande do Norte - TJRN. Professor da Universidade do Estado do Rio Grande do Norte - UERN e da Faculdade Mater Christi. Mossoró, Rio Grande do Norte, Brasil. email: jthalles@hotmail.com.
} 
ANDRADE, Júlio Thalles de Oliveira. Os direitos fundamentais sociais à luz do princípio da vedação ao retrocesso social. Revista Eletrônica Direito e Política, Programa de Pós-Graduação Stricto Sensu em Ciência Jurídica da UNIVALI, Itajaí, v.11, n.1, $1^{\circ}$ quadrimestre de 2016. Disponível em: www.univali.br/direitoepolitica - ISSN 1980-7791.

\section{ABSTRACT}

The article discusses the role of principles in national law, particularly dealing on the principle of sealing the social regression. For this, it adopts the view that social rights are fundamental rights, prompting discussion of the grounds used to seal the alteration or deletion of an infra legislation implementing a social right already enshrined. The absence of concrete and justifying criteria for limiting the realization of social rights can lead to an affront to the principle of sealing the social regression, disregarding It is thus the principle of human dignity. For the preparation of this study, we sought to benefit in the literature, being adopted, therefore, the hypothetical-deductive method.

KEYWORDS: Fundamental rights. Social rights. Principle prohibiting the social backlash.

\section{INTRODUÇÃO}

Um dos desafios da República Federativa do Brasil é a busca pela manutenção e efetivação dos direitos fundamentais, já integrados ao patrimônio da humanidade. Oriundos do processo de constitucionalização dos direitos do homem, ganharam um impulso especial com a Declaração Universal dos Direitos Humanos, adotada pela Organização das Nações Unidas no ano de 1948.

Este trabalho visa discutir acerca dos direitos fundamentais sociais, em especial, tratando do princípio da vedação ao retrocesso social, levando em conta que os direitos sociais, além de estarem sujeitos a uma regulamentação legislativa e a condicionamentos econômico-financeiros, sendo classificados como direitos fundamentais, não podem ser deixados ao livre alvitre do legislador.

A discussão aqui travada gira em torno da proibição do retrocesso social que possui papel de restringir a liberdade de conformação do legislador na revogação ou alteração da legislação infraconstitucional que represente a implementação de direitos fundamentais sociais implícitos ou explícitos na Constituição Federal, evitando restringir normas que implementem os direitos sociais.

Nesse sentido, ao legislador não cabe a decisão sobre a conveniência ou a oportunidade de regulamentar determinado direito social, vindo o princípio da 
ANDRADE, Júlio Thalles de Oliveira. Os direitos fundamentais sociais à luz do princípio da vedação ao retrocesso social. Revista Eletrônica Direito e Política, Programa de Pós-Graduação Stricto Sensu em Ciência Jurídica da UNIVALI, Itajaí, v.11, n.1, $1^{\circ}$ quadrimestre de 2016. Disponível em: www.univali.br/direitoepolitica - ISSN 1980-7791.

vedação do retrocesso social se impor pela fundamentalidade desses direitos e pelo regime de progressividade que a eles se aplica, vedando ao Estadolegislador retroceder de forma arbitrária, desproporcional, em relação à regulamentação legislativa de um direito social.

Para isso, o presente estudo abordará a sistematicidade dos princípios no ordenamento jurídico, delimitando-os, para depois, adentrar na discussão acerca do princípio da vedação ao retrocesso social.

\section{DELIMITAÇÃo do CONCEITO DE PRINCÍPIOS NO ORDENAMENTO JURÍDICO}

Para se compreender o que o presente texto buscar transmitir acerca do princípio da vedação ao retrocesso social, faz-se útil esclarecer a concepção que se toma aqui para o papel dos princípios no ordenamento jurídico.

Levando-se em consideração que as normas jurídicas podem assumir a forma de regras e de princípios, para se distingui-los, há que possuir alguns critérios, já comentados por Canotilho ${ }^{2}$, como o grau de abstração, o grau de determinabilidade, a fundamentalidade, a proximidade da ideia de direito e a natureza normogenética.

Em relação ao primeiro critério, os princípios são normas que possuem um grau de abstração maior do que as regras.

No que concerne a determinabilidade na aplicação do caso concreto, as regras são aplicadas diretamente, enquanto os princípios, por serem indeterminados e vagos, não possuem mediações concretizadoras.

Quando se parte para o grau de fundamentalidade na sistemática das fontes do direito, Canotilho afirma que os princípios possuem natureza fundamental no

\footnotetext{
${ }^{2}$ CANOTILHO, J. J. Gomes. Direito Constitucional e Teoria da Constituição. 4. ed. Coimbra: Coimbra, 2000, p. 1124.
} 
ANDRADE, Júlio Thalles de Oliveira. Os direitos fundamentais sociais à luz do princípio da vedação ao retrocesso social. Revista Eletrônica Direito e Política, Programa de Pós-Graduação Stricto Sensu em Ciência Jurídica da UNIVALI, Itajaí, v.11, n.1, $1^{\circ}$ quadrimestre de 2016. Disponível em: www.univali.br/direitoepolitica - ISSN 1980-7791.

ordenamento em razão da posição hierárquica que possuem no sistema das fontes.

Quanto à proximidade da ideia de direito, as regras podem ser normas vinculativas com um conteúdo funcional, enquanto os princípios, na visão de Ronald Dworkin, são "standards" juridicamente vinculantes nas exigências de justiça ou na ideia de direito.

Paulo Bonavides ${ }^{3}$ afirma que os princípios nem sempre pertencem ao mundo do ser, sendo verdades objetivas de caráter geral. Estes devem possuir normatividade. Nesta mesma obra ele aduz que Riccardo Guastini verificou a existência de 06 conceitos de princípios utilizados pela doutrina e jurisprudência, sendo primeiramente entendidos como normas com alto grau de generalidade; em segundo, como normas dotadas de indeterminação, necessitando de interpretação; em terceiro, como norma dotada de caráter programático; em quarto os utiliza como norma de hierarquia elevada; em quinto usa-os como norma fundamental e, por fim, usa-os como normas dirigidas aos órgãos de aplicação.

Para Dworkin, tanto as regras quanto os princípios são mandamentos cuja validade deontológica exprime uma obrigação. As regras são normas concretas e específicas e os princípios são gerais e necessitam de interpretação. Ambos não possuem estrutura teleológica.

Portanto, os princípios são fundamento para as regras, encontrando-se na base, desempenhando, portanto, função normogenética fundante. As regras devem ser entendidas como preceitos menos amplos e axiologicamente inferiores aos princípios, existindo justamente para dar concretude aos princípios.

Complementando e somando a essa ideia, Juarez Freitas entende os sistemas jurídicos como sendo:

3 BONAVIDES, Paulo. Curso de Direito Constitucional. 13. ed. São Paulo: Malheiros, 2004, p. 260. 
ANDRADE, Júlio Thalles de Oliveira. Os direitos fundamentais sociais à luz do princípio da vedação ao retrocesso social. Revista Eletrônica Direito e Política, Programa de Pós-Graduação Stricto Sensu em Ciência Jurídica da UNIVALI, Itajaí, v.11, n.1, $1^{\circ}$ quadrimestre de 2016. Disponível em: www.univali.br/direitoepolitica - ISSN 1980-7791.

[...] uma rede axiológica e hierarquizada topicamente de princípios fundamentais, de normas estritas (ou regras) e de valores jurídicos cuja função é a de, evitando ou superando antinomias em sentido lato, dar cumprimento aos objetivos justificadores do Estado Democrático, assim como se encontram consubstanciados, expressa ou implicitamente, na Constituição ${ }^{4}$.

A diferença do conceito de Juarez Freitas para outros autores, como, por exemplo, Ronald Dworkin é que este coloca o sistema como um conjunto de regras e princípios e estes dotados de valores, enquanto Juarez Freitas coloca o sistema como formado por regras, princípios e valores, retirando-se os valores do conceito de princípios e colocando-os como uma nova vertente. Essa diferenciação não possui um efeito prático relevante para o estudo a que pretende o presente trabalho.

Vê-se que a diferenciação entre regras e princípios não é considerada uma tarefa fácil, necessitando-se analisar vários pressupostos para se chegar ao entendimento correto e esclarecedor, mas essa dificuldade é gerada pela problemática em se definir a função que os princípios exercem no ordenamento jurídico, bem como se eles possuem um denominador comum com as regras.

Para se chegar a essa concepção, entra em cena a figura do hermeneuta que tem que possuir a visão de que o ato de interpretar deve objetivar não um texto, mas o sentido que ele representa e que ele foi determinado por outro ato interpretativo, ou seja, o da autoridade competente, que é condicionado por uma série de fatores que podem modificá-lo.

O ordenamento exige a presença de certos princípios reguladores da atividade interpretativa, lembrando-se que os princípios possuem um grau de generalidade e abstração maior do que as regras.

\footnotetext{
${ }^{4}$ FREITAS, Juarez. A Interpretação Sistemática do Direito. 4. ed. São Paulo: Malheiros, 2004, p. 54.
} 
ANDRADE, Júlio Thalles de Oliveira. Os direitos fundamentais sociais à luz do princípio da vedação ao retrocesso social. Revista Eletrônica Direito e Política, Programa de Pós-Graduação Stricto Sensu em Ciência Jurídica da UNIVALI, Itajaí, v.11, n.1, $1^{\circ}$ quadrimestre de 2016. Disponível em: www.univali.br/direitoepolitica - ISSN 1980-7791.

Sabe-se que os princípios trazem situações de validade e peso, enquanto as regras apenas trazem situações de validade, sendo necessária sua alteração se elas não são corretas.

Uma interpretação que possuísse princípios sempre abertos não obteria uma decisão, daí a necessidade de um princípio dogmático que possa impedir o retrocesso ao infinito, pois também a sua identificação é materialmente aberta. Isso manifesta a liberdade que o intérprete possui, sendo um pressuposto da hermenêutica jurídica.

É justamente a existência de princípios e regras que fornecem para a sociedade a compreensão do Direito Constitucional como um sistema aberto, contrabalanceado, possibilitador de uma descodificação, trazendo-se, na visão de Alexy, um constitucionalismo "adequado".

Não é diferente a opinião de Canotilho, quando aduz que:

Esta perspectiva teorético-jurídica do sistema constitucional, tendencialmente principialista, é de particular importância, não só porque fornece suportes rigorosos para solucionar certos problemas metódicos, mas também porque permite respirar, legitimar, enraizar e caminhar o próprio sistema. A respiração obtém-se através da textura aberta dos princípios; a legitimidade entrevê-se na ideia de os princípios consagrarem valores (liberdade, democracia, dignidade) fundamentadores da ordem jurídica e disporem de capacidade deontológica de justificação $(\ldots) .^{5}$

Se o ordenamento jurídico estivesse formado apenas por regras, o sistema seria considerado fechado, com um disciplinamento legal exaustivo e, em tese, seguro, no entanto, impedido de abarcar novas situações trazidas pelo avanço social, possuidor de um legalismo exacerbado. Caso, ao contrário, o ordenamento fosse constituído apenas por princípios, que são abstratos e indeterminados, o sistema seria inseguro e incapaz de reduzir a complexidade do próprio ordenamento.

${ }^{5}$ CANOTILHO, J. J. Gomes. Direito Constitucional e Teoria da Constituição. p. 1127. 
ANDRADE, Júlio Thalles de Oliveira. Os direitos fundamentais sociais à luz do princípio da vedação ao retrocesso social. Revista Eletrônica Direito e Política, Programa de Pós-Graduação Stricto Sensu em Ciência Jurídica da UNIVALI, Itajaí, v.11, n.1, $1^{\circ}$ quadrimestre de 2016. Disponível em: www.univali.br/direitoepolitica - ISSN 1980-7791.

Desse modo, para se compreender essa "rede" de princípios e regras, não se pode utilizar da lógica do "tudo-ou-nada", devendo sim, ser dialética sempre no campo dos princípios e das regras, não se constatando uma zona de vinculação pura sem espaço à ponderação ou à hierarquização axiológica ${ }^{6}$.

A partir dessa delimitação, chega-se a uma ideia mais clara do que se entende por princípio e parte-se para o estudo pormenorizado do princípio da vedação ao retrocesso social.

\section{O PRINCÍPIO DA VEDAÇÃO AO RETROCESSO SOCIAL}

Após estabelecer o que se entende por princípios e qual o seu papel no ordenamento jurídico, cabe neste momento buscar a definição e o delineamento do princípio da vedação ao retrocesso social.

Este princípio proíbe o Legislador de suprimir ou alterar normas infraconstitucionais que efetivem normas constitucionais de direitos sociais de forma a afetar sua eficácia.

Para Ingo Wolfgang Sarlet, a vedação ao retrocesso social está relacionada à necessidade de manutenção da segurança jurídica:

A problemática da proibição de retrocesso guarda íntima relação com a noção de segurança jurídica. [...] a idéia de segurança jurídica encontra-se umbilicalmente vinculada também à própria noção de dignidade da pessoa humana. Com efeito, a dignidade não restará suficientemente respeitada e protegida em todo o lugar onde as pessoas estejam sendo atingidas por um tal nível de instabilidade jurídica que não estejam mais em condições de, com um mínimo de segurança e tranquilidade, confiar nas instituições

\footnotetext{
${ }^{6}$ FREITAS, Juarez. A Interpretação Sistemática do Direito. p. 54.
} 
ANDRADE, Júlio Thalles de Oliveira. Os direitos fundamentais sociais à luz do princípio da vedação ao retrocesso social. Revista Eletrônica Direito e Política, Programa de Pós-Graduação Stricto Sensu em Ciência Jurídica da UNIVALI, Itajaí, v.11, n.1, $1^{\circ}$ quadrimestre de 2016. Disponível em: www.univali.br/direitoepolitica - ISSN 1980-7791.

sociais e estatais (incluindo o Direito) e numa certa estabilidade das suas próprias posições jurídicas. ${ }^{7}$

O referido autor, levando em consideração as exigências da segurança jurídica, deixa claro que a dignidade da pessoa humana não exige somente a proteção em face de atos de caráter retroativo do Estado, mas também de atos que se apresentem retrocessivos. Dá para vislumbrar nas linhas tratadas por Sarlet que o princípio da vedação ao retrocesso representaria uma faceta do princípio da segurança jurídica, configurando um subprincípio.

Para J.J. Canotilho, os direitos sociais, uma vez tendo obtido certo grau de realização, passam a constituir tanto uma garantia institucional quanto um direito subjetivo, fato limitador da reversibilidade dos direitos adquiridos, o que para ele, violaria o princípio da proteção da confiança e da segurança dos cidadãos no âmbito econômico, social e cultural.

O autor acima entende que existe uma vinculação entre a proibição ao retrocesso social e a segurança jurídica. No entanto, um não representaria uma mera faceta do outro.

Não há como interpretar a Constituição em outro sentido senão naquele que busque uma progressiva concretização dos direitos sociais, ainda mais se for analisado sob a égide do princípio da dignidade da pessoa humana.

Neste sentido é o pensamento de Lenio Luiz Streck, in verbis:

Dito de outro modo, a Constituição não tem somente a tarefa de apontar para o futuro. Tem, igualmente, a relevante função de proteger os direitos já conquistados. Desse modo, mediante a utilização da principiologia constitucional (explícita ou implícita), é possível combater alterações feitas por maiorias políticas eventuais, que

7 SARLET, Ingo Wolfgang. Algumas notas em torno da proibição de retrocesso na esfera dos direitos fundamentais. In: Direito \& Justiça, Porto Alegre, v. 32, n. 1, p. 09-50, jan.jun. 2006. 
ANDRADE, Júlio Thalles de Oliveira. Os direitos fundamentais sociais à luz do princípio da vedação ao retrocesso social. Revista Eletrônica Direito e Política, Programa de Pós-Graduação Stricto Sensu em Ciência Jurídica da UNIVALI, Itajaí, v.11, n.1, $1^{\circ}$ quadrimestre de 2016. Disponível em: www.univali.br/direitoepolitica - ISSN 1980-7791.

legislando na contramão da programaticidade constitucional, retiram (ou tentam retirar) conquistas da sociedade. ${ }^{8}$

O pensamento de Streck não foge da ideia de que o conteúdo do princípio em tela guarda proximidade com o princípio da segurança jurídica, não se confundindo, no entanto, com o mesmo. Parece demonstrar que representaria uma expressão do princípio do Estado Social, implícito na Constituição Federal.

Vale salientar que a vedação ao retrocesso social não importa em uma vedação absoluta à movimentação retrocessiva, pois, para sua aplicação, deverá sempre ser realizada uma ponderação com as regras e princípios que concretamente atuem em determinada situação, a fim de saber se o ato é ou não permitido constitucionalmente.

Dentre os princípios que aparecem com destaque na análise do princípio da vedação ao retrocesso social estão a reserva do possível e o mínimo existencial, analisados a seguir.

\section{RESERVA DO POSSÍVEL E MÍNIMO EXISTENCIAL FRENTE À VEDAÇÃo AO RETROCESSO SOCIAL}

Para Canotilho ${ }^{9}$, os direitos sociais já alcançados passam a figurar como garantia institucional e direito subjetivo. Isso leva a duas situações: primeiro, impede a supressão de direitos já conquistados e, segundo, representa uma obrigação de empenho por uma política afinada com os direitos concretizados.

Seguindo esta linha, surge o embate deste princípio com a reserva do possível. Esta, quando é utilizada como argumento para suprimir alguma política pública

\footnotetext{
8 STRECK, Lenio Luiz. Hermenêutica Jurídica $\mathbf{e}(\mathbf{m})$ Crise. 3. ed. Porto Alegre: Livraria do Advogado Editora, 2001, p. 55.

${ }^{9}$ CANOTILHO, José Joaquim Gomes. Direito Constitucional. Coimbra: Livraria Almedina, 1991, p. 474.
} 
ANDRADE, Júlio Thalles de Oliveira. Os direitos fundamentais sociais à luz do princípio da vedação ao retrocesso social. Revista Eletrônica Direito e Política, Programa de Pós-Graduação Stricto Sensu em Ciência Jurídica da UNIVALI, Itajaí, v.11, n.1, $1^{\circ}$ quadrimestre de 2016. Disponível em: www.univali.br/direitoepolitica - ISSN 1980-7791.

concretizadora de direitos sociais, poderá gerar uma violação ao princípio da vedação ao retrocesso social.

Há que se observar que a concretização de direitos sociais dentro de uma reserva do possível não quer dizer que ela constitua os direitos fundamentais como limite imanente.

Como todos os princípios possuem um caráter relativo, eventuais ajustes perpetrados em sede de direitos sociais que possam representar um retrocesso, devem ser devidamente justificáveis. Daí, a justificativa da reserva do possível como fundamento a medidas (mesmo que de caráter pro futuro) que tragam um retrocesso no âmbito das conquistas sociais não poderá valer sem uma justificativa correlacionada com todo o sistema constitucional, sob pena de ocorrer violação do mínimo em conteúdo exigível quando em foco a concretização de direitos sociais.

Conforme já se referiu em linhas passadas, os direitos fundamentais, na qualidade de princípios, podem colidir sem que percam validade. Na linha de raciocínio de $A \operatorname{lexy}{ }^{10}$, podem ocorrer situações em que um princípio irá prevalecer sobre outro em certas situações. Essa atribuição de peso maior a um dos princípios em conflito surge como solução ao conflito indicado pelo Tribunal Constitucional Alemão, sob a nomenclatura de ponderação ou sopesamento (Abwägung).

Os conflitos existentes entre direitos sociais dar-se-ão, em especial, sob o aspecto da escassez de recursos para a sua concretização, de forma tal que a atribuição de maior peso a um passará pela ponderação. A reserva do possível não pode, por si só, levar ao esvaziamento de um direito sem que passe pela ponderação.

${ }^{10}$ ALEXY, Robert. Teoria dos direitos fundamentais. Tradução de Virgílio Afonso da Silva. São Paulo: Malheiros, 2008, p. 93. 
ANDRADE, Júlio Thalles de Oliveira. Os direitos fundamentais sociais à luz do princípio da vedação ao retrocesso social. Revista Eletrônica Direito e Política, Programa de Pós-Graduação Stricto Sensu em Ciência Jurídica da UNIVALI, Itajaí, v.11, n.1, $1^{0}$ quadrimestre de 2016. Disponível em: www.univali.br/direitoepolitica - ISSN 1980-7791.

Pode-se observar que o Estado deve se organizar no sentido de minimizar as desigualdades sociais, ou seja, deverá garantir um mínimo de participação nos bens da vida, buscando a redistribuição na sociedade. Eurico Bitencourt Neto aduz que:

O Estado social significa, para além da garantia de um mínimo existencial, a busca de uma sociedade de bem-estar para todos, na medida das possibilidades de um sistema capitalista, em que as liberdades individuais e a propriedade privada também contam com proteção constitucional.

Deve-se buscar a adequação de uma estrutura que respeite padrões mínimos de dignidade, pois a liberdade de conformação do legislador encontrará sempre um limite mínimo em condições materiais indispensáveis para uma vida digna.

O mínimo existencial depende de uma série de fatores que podem estar ligados às condições individuais ou a circunstâncias socioeconômicas e culturais, não podendo ser resumido numa fórmula. Pode-se dizer que os direitos vinculados ao mínimo existencial representam direitos subjetivos definitivos, não significando que esses direitos sejam absolutos, podendo sofrer alguma restrição, inclusive em razão dos limites impostos pela reserva do possível.

Dessa forma, a reserva do possível somente poderá atuar como argumento válido quanto estiver demonstrado pelos Poderes Públicos que eventual restrição aos direitos sociais foi fruto de ponderação entre princípios que conflitaram, atendendo a proporcionalidade e preservando o conteúdo mínimo necessário para a garantia da dignidade, de forma a evitar o retrocesso social.

\section{PRINCÍPIO DA VEDAÇÃo AO RETROCESSO NA ORDEM CONSTITUCIONAL BRASILEIRA}

É como princípio implícito que a vedação ao retrocesso social é consagrada no ordenamento constitucional brasileiro. 
ANDRADE, Júlio Thalles de Oliveira. Os direitos fundamentais sociais à luz do princípio da vedação ao retrocesso social. Revista Eletrônica Direito e Política, Programa de Pós-Graduação Stricto Sensu em Ciência Jurídica da UNIVALI, Itajaí, v.11, n.1, $1^{\circ}$ quadrimestre de 2016. Disponível em: www.univali.br/direitoepolitica - ISSN 1980-7791.

Luís Roberto Barroso ${ }^{11}$ afirma que:

[...] por este princípio, que não é expresso, mas decorre do sistema jurídico-constitucional, entende-se que se uma lei, ao regulamentar um mandamento constitucional, instituir determinado direito, ele se incorpora ao patrimônio jurídico da cidadania e não pode ser absolutamente suprimido.

A ideia que surge do princípio da vedação ao retrocesso social é de um direito subjetivo negativo, podendo-se impugnar por meio judicial qualquer medida que conflite com a Constituição Federal, bem como quaisquer medidas do Poder Legislativo que subtraiam de uma norma constitucional o grau de concretização anterior que Ihe foi concedido.

Ingo Sarlet entende que a vedação ao retrocesso resulta diretamente do princípio da maximização da eficácia de todas as normas de direitos fundamentais.

Não há como esquecer que a função legiferante deve possuir autonomia, pois o legislador não pode ser considerado um mero órgão de execução das decisões constitucionais. Ademais, isso acabaria conduzindo a uma espécie de transmutação das normas infraconstitucionais em direito constitucional, inviabilizando o próprio desenvolvimento deste.

Sarlet arremata essa ideia comentando que:

Assim, a proibição de retrocesso assume (como parece ter sido suficientemente fundamentado) feições de verdadeiro princípio constitucional fundamental implícito, que pode ser reconduzido tanto ao princípio do Estado de Direito (no âmbito da proteção da confiança e da estabilidade das relações jurídicas inerentes à segurança jurídica), quanto ao princípio do Estado Social, na condição de garantia da manutenção dos graus mínimos de segurança social alcançados, sendo, de resto, corolário da máxima eficácia e efetividade das normas de direitos fundamentais sociais e do

${ }^{11}$ BARROSO, Luís Roberto. O Direito Constitucional e a Efetividade de suas normas. 5. ed. Rio de Janeiro: Renovar, 2001, p. 158. 
ANDRADE, Júlio Thalles de Oliveira. Os direitos fundamentais sociais à luz do princípio da vedação ao retrocesso social. Revista Eletrônica Direito e Política, Programa de Pós-Graduação Stricto Sensu em Ciência Jurídica da UNIVALI, Itajaí, v.11, n.1, $1^{\circ}$ quadrimestre de 2016. Disponível em: www.univali.br/direitoepolitica - ISSN 1980-7791.

direito à segurança jurídica, assim como da própria dignidade da pessoa humana ${ }^{12}$.

Há que se observar que a proibição do retrocesso social, por se tratar de um princípio, aceita certas reduções no âmbito das conquistas sociais ao nível infraconstitucional, não se admitindo sua supressão pura e simples, levando em conta que o núcleo essencial dos direitos sociais já efetivado pelo Poder Legislativo encontra-se constitucionalmente assegurado contra medidas estatais que levem à sua revogação pura e simples.

Importa saber qual seria o alcance necessário do princípio em tela, aferindo-se seus limites de aplicação. A vedação ao retrocesso representa uma proteção que vai além da proteção conferida pelas figuras do direito adquirido e da coisa julgada. Daí se afirmar que qualquer medida restritiva em matéria de direitos sociais, desde o início, já deve ser vista com reservas, sendo submetida a uma presunção relativa de inconstitucionalidade, sujeitando-se a controle quanto à proporcionalidade.

Deve ser realizada uma fiscalização da constitucionalidade de forma preventiva, analisando-se a justificativa utilizada para se afetar o princípio da proibição do retrocesso, não se esquecendo de que além da dignidade da pessoa humana e do mínimo existencial, outras noções têm que ser analisadas, como, por exemplo, a segurança jurídica, a proteção da confiança e a isonomia, para que o princípio em tela atue como um padrão mínimo de continuidade do ordenamento jurídico.

O legislador nacional não pode pura e simplesmente expurgar as normas legais que concretizam direitos sociais, pois se estaria retirando a eficácia jurídica das normas constitucionais, afetando em cheio o princípio da dignidade da pessoa humana.

\footnotetext{
12 SARLET, Ingo Wolfgang. A eficácia dos direitos fundamentais: uma teoria geral dos direitos fundamentais na perspectiva constitucional. 10. ed. Porto Alegre: Livraria do Advogado, 2009, p. 450.
} 
ANDRADE, Júlio Thalles de Oliveira. Os direitos fundamentais sociais à luz do princípio da vedação ao retrocesso social. Revista Eletrônica Direito e Política, Programa de Pós-Graduação Stricto Sensu em Ciência Jurídica da UNIVALI, Itajaí, v.11, n.1, $1^{\circ}$ quadrimestre de 2016. Disponível em: www.univali.br/direitoepolitica - ISSN 1980-7791.

Não há como negar que o ordenamento jurídico brasileiro criou uma espécie de "eficácia bloqueadora do retrocesso", derivando a proibição do retrocesso do princípio da maximização da eficácia das normas de direitos fundamentais, quando outorgou ao parágrafo $1^{\circ}$, do art. 50, da Constituição Federal a proteção efetiva dos direitos fundamentais não somente contra a atuação do poder de reforma da Constituição, mas também contra o legislador ordinário e os outros órgãos estatais.

A problemática da vedação ao retrocesso social foi apenas tangenciada pelo Supremo Tribunal Federal, mas essa temática não deve estar longe de ser enfrentada a fundo pelo guardião da Constituição Federal, pois além do tema estar sendo discutido com frequência pela doutrina nacional, a sistemática econômica de um mundo globalizado tem impulsionado o legislador a tomar decisões que atingem os direitos fundamentais sociais, fato que propicia uma análise da constitucionalidade de tais medidas.

Dessa forma, os direitos sociais devem ser protegidos de ações que tentem invadir seu núcleo essencial, atingindo as exigências da proporcionalidade e os demais princípios que fundamentam a Constituição Federal de 1988.

\section{A AMPLITUDE DO PRINCÍPIO DA VEDAÇÃO AO RETROCESSO SOCIAL}

Em relação ao reconhecimento da existência do princípio da vedação ao retrocesso social em matéria dos direitos fundamentais, não pairam maiores dúvidas, em especial em razão das vozes que defendem o instituto e dos argumentos utilizados para justifica-lo.

No entanto, controvérsias ainda surgem quando se parte para a amplitude da proteção outorgada pelo princípio, pois se sabe que a proteção contra o retrocesso social não pode assumir um caráter absoluto, em especial no que está relacionado com a concretização dos direitos sociais a prestações. 
ANDRADE, Júlio Thalles de Oliveira. Os direitos fundamentais sociais à luz do princípio da vedação ao retrocesso social. Revista Eletrônica Direito e Política, Programa de Pós-Graduação Stricto Sensu em Ciência Jurídica da UNIVALI, Itajaí, v.11, n.1, $1^{\circ}$ quadrimestre de 2016. Disponível em: www.univali.br/direitoepolitica - ISSN 1980-7791.

Ingo Sarlet, analisando o tema, aduz que:

[...] uma proibição absoluta não apenas implica a afetação substancial da necessária possibilidade de revisão que é peculiar à função legislativa, mas também desconsidera a indispensável possibilidade (e necessidade) de reavaliação global e permanente das metas da ação estatal e do próprio desempenho na consecução de tais metas, ou seja, a reavaliação mesmo dos meios utilizados para a realização dos fins estatais, com destaque para a efetivação dos direitos fundamentais ${ }^{13}$.

A instituição da vedação ao retrocesso social como se regra absoluta fosse, pode trazer uma incompatibilização com outras regras e princípios constitucionais, tais como o princípio democrático, o qual informa a liberdade de conformação do legislador (infraconstitucional). Determinadas decisões, fundamentadas neste último princípio, podem representar um recuo estratégico quando circunstâncias fáticas exigirem a flexibilização ou abolição de uma legislação que represente a implementação de direitos fundamentais sociais, seja possibilitando um avanço ainda maior no futuro, seja para evitar uma crise sistemática comprometedora não só daquela implementação específica, mas também de outras, inclusive de todo o sistema de proteção social previsto na Constituição Federal.

Neste cotejo, conferir um caráter absoluto à vedação ao retrocesso seria reduzir a atividade legislativa a uma mera executora da Constituição, além de expurgar a ideia de segurança social buscada pela Carta Magna.

Por ser o núcleo essencial dos direitos sociais que vincula o ordenamento jurídico contra retrocessos, cabe analisar os contornos da dignidade da pessoa humana para se delimitar o princípio da vedação ao retrocesso.

Neste sentido, Flávia Piovesan comenta acerca da essencialidade do princípio da dignidade da pessoa humana, afirmando que:

${ }^{13}$ SARLET, Ingo Wolfgang. A eficácia dos direitos fundamentais: uma teoria geral dos direitos fundamentais na perspectiva constitucional. p. 448. 
ANDRADE, Júlio Thalles de Oliveira. Os direitos fundamentais sociais à luz do princípio da vedação ao retrocesso social. Revista Eletrônica Direito e Política, Programa de Pós-Graduação Stricto Sensu em Ciência Jurídica da UNIVALI, Itajaí, v.11, n.1, $1^{\circ}$ quadrimestre de 2016. Disponível em: www.univali.br/direitoepolitica - ISSN 1980-7791.

A dignidade da pessoa humana, vê-se assim, está erigida como princípio matriz da Constituição, imprimindo-lhe unidade de sentido, condicionando a interpretação das suas normas e revelando-se, ao lado dos Direitos e Garantias Fundamentais, como cânone constitucional que incorpora as exigências de justiça e dos valores éticos, conferindo suporte axiológico a todo o sistema jurídico brasileiro ${ }^{14}$.

Esses direitos sociais aqui discutidos possuem caráter prestacional, ou seja, englobam prestações materiais indispensáveis para se falar em vida digna. Para se assegurar o exercício de liberdades fundamentais, tem-se que se buscar estudar o mínimo existencial e o núcleo essencial para se garantir a dignidade da pessoa humana.

$\mathrm{Na}$ impossibilidade de manutenção de determinado direito já consagrado, tomar uma medida de caráter retrocessivo, não atingindo o princípio da proibição do retrocesso social, deve contar com uma justificativa de cunho constitucional, resguardando-se o núcleo essencial dos direitos sociais.

Ingo Sarlet afirma que:

Considerando que o núcleo essencial dos direitos fundamentais, inclusive sociais, nem sempre corresponde ao seu conteúdo em dignidade (que poderá ser variável, a depender do direito fundamental em causa) é de se admitir até mesmo a eventual inconstitucionalidade de medidas que - mesmo não afetando diretamente a dignidade da pessoa humana - inequivocamente estejam a invadir o núcleo essencial. Que também no âmbito da proibição de retrocesso importa que se tenha sempre presente a circunstância de que o conteúdo do mínimo existencial para uma vida digna encontra-se condicionado pelas circunstâncias históricas, geográficas, sociais, econômicas e culturais em cada lugar e momento em que estiver em causa, resulta evidente e vai aqui assumido como pressuposto de nossa análise. ${ }^{15}$

${ }^{14}$ PIOVESAN, Flávia. Direitos Humanos e o Direito Constitucional Internacional. 13. ed. São Paulo: Saraiva, 2012, p. 85.

${ }^{15}$ SARLET, Ingo Wolfgang. A eficácia dos direitos fundamentais: uma teoria geral dos direitos fundamentais na perspectiva constitucional. p. 105. 
ANDRADE, Júlio Thalles de Oliveira. Os direitos fundamentais sociais à luz do princípio da vedação ao retrocesso social. Revista Eletrônica Direito e Política, Programa de Pós-Graduação Stricto Sensu em Ciência Jurídica da UNIVALI, Itajaí, v.11, n.1, $1^{\circ}$ quadrimestre de 2016. Disponível em: www.univali.br/direitoepolitica - ISSN 1980-7791.

Não se pode esquecer, na análise da proibição do retrocesso social, do princípio da segurança jurídica, o qual existe para fornecer e dar um norte a situações paradigmáticas como a discutida aqui, fornecendo confiança e estabilidade numa situação fática.

Além desse, o princípio da proteção da confiança também impõe que seja realizada uma ponderação quando da ocorrência de uma restrição no âmbito social, ou seja, deve ser realizada uma hierarquização entre o dano provocado pela legislação restritiva e a confiança individual. Mesmo que os cidadãos não possuam direito a uma determinada posição legislativa, caso ocorra possibilidade de violação de situações jurídicas já consolidadas, o interesse particular deverá ser levado em conta, necessitando-se de uma meticulosa ponderação entre a intenção do legislador e a necessidade de proteção da confiança.

Em algumas hipóteses, tem-se observado que o legislador, surgindo a necessidade de intervir numa posição jurídica já consolidada, este o faz estabelecendo regras de transição para que os atingidos possam se adaptar à nova realidade jurídica.

Partindo-se das premissas citadas acima, o surgimento de uma medida restritiva de uma posição social deve possuir como pressuposto indispensável um dever de motivação para que seja legitimada a atuação do poder público, para que sejam alcançados os princípios da proporcionalidade e isonomia.

A ordem jurídica só pode ter continuidade e progressividade se houver segurança jurídica, atuando o princípio da proibição do retrocesso social como norte assecuratório da evolução social, garantindo a segurança dos cidadãos no âmbito econômico, social e cultural.

\section{CONSIDERAÇÕES FINAIS}


ANDRADE, Júlio Thalles de Oliveira. Os direitos fundamentais sociais à luz do princípio da vedação ao retrocesso social. Revista Eletrônica Direito e Política, Programa de Pós-Graduação Stricto Sensu em Ciência Jurídica da UNIVALI, Itajaí, v.11, n.1, $1^{\circ}$ quadrimestre de 2016. Disponível em: www.univali.br/direitoepolitica - ISSN 1980-7791.

A Constituição deve ser vista como uma unidade, privilegiando os valores sociais, elegendo a dignidade humana como valor essencial, aproximando-se aos ideais kantianos de moralidade, dignidade e paz que o levam a crer que o ser deve existir como um fim em si mesmo e nunca como um meio.

O ordenamento jurídico deve ser visto como um sistema, possuindo ao lado das normas legais, os princípios que trazem as exigências de justiça e de valores éticos. Esses princípios representam o suporte axiológico que traz coerência interna e estruturante do ordenamento jurídico.

Partindo-se desse pressuposto, o ordenamento jurídico brasileiro deve reconhecer o princípio constitucional da vedação ao retrocesso social, principalmente para que o legislador nacional, além de ficar ainda mais vinculado diretamente à vontade da Constituição, também reconheça quais são os valores centrais da ordem jurídica, em especial a efetivação do princípio da dignidade humana.

Neste sentido, deve ser construída uma argumentação que forneça sustentabilidade ao princípio da vedação ao retrocesso social, baseando-se na supremacia constitucional, nos direitos fundamentais sociais, no princípio da máxima efetividade, no mínimo existencial, segurança jurídica, proteção da confiança, dentre outros.

Para se evitar ou reverter um ato legislativo que incida em retrocesso social, há necessidade de argumentos expressos e bem fundamentados, capazes de demonstrar que o legislador atuou com retrocesso, de forma a evitar violação ao princípio da separação de poderes e uma hipertrofia do Poder Judiciário.

A técnica da ponderação deve ser utilizada, em especial, quando estiver em jogo o princípio da reserva do possível e o mínimo existencial, impedindo de forma razoável e proporcional o retrocesso social.

Restou demonstrado que o princípio da vedação ao retrocesso social constitui uma das ferramentas para assegurar a proteção dos direitos sociais contra 
ANDRADE, Júlio Thalles de Oliveira. Os direitos fundamentais sociais à luz do princípio da vedação ao retrocesso social. Revista Eletrônica Direito e Política, Programa de Pós-Graduação Stricto Sensu em Ciência Jurídica da UNIVALI, Itajaí, v.11, n.1, $1^{\circ}$ quadrimestre de 2016. Disponível em: www.univali.br/direitoepolitica - ISSN 1980-7791.

exclusão ou redução de direitos pelos poderes constituídos, viabilizando um direito constitucional solidário e inclusivo.

\section{REFERÊNCIAS DAS FONTES CITADAS}

ALEXY, Robert. Teoria dos direitos fundamentais. Tradução de Virgílio Afonso da Silva. São Paulo: Malheiros, 2008.

BARROSO, Luís Roberto. O Direito Constitucional e a Efetividade de suas normas. 5. ed. Rio de Janeiro: Renovar, 2001.

BONAVIDES, Paulo. Curso de Direito Constitucional. 13. ed. São Paulo: Malheiros, 2004.

CANOTILHO, José Joaquim Gomes. Direito Constitucional e Teoria da Constituição. 4. ed. Coimbra: Coimbra, 2000.

Direito Constitucional. Coimbra: Livraria Almedina, 1991.

DWORKIN, Ronald. Levando os Direitos a sério. São Paulo: Martins Fontes, 2010.

O império do direito. São Paulo: Martins Fontes: 2003.

Uma questão de princípio. São Paulo: Martins Fontes, 2000.

FREITAS, Juarez. A Interpretação Sistemática do Direito. 4. ed. São Paulo: Malheiros, 2004.

PIOVESAN, Flávia. Direitos Humanos e o Direito Constitucional Internacional. 13. ed. São Paulo: Saraiva, 2012.

SARLET, Ingo Wolfgang. A eficácia dos direitos fundamentais: uma teoria geral dos direitos fundamentais na perspectiva constitucional. 10. ed. Porto Alegre: Livraria do Advogado, 2009.

Algumas notas em torno da proibição de retrocesso na esfera dos direitos fundamentais. In: Direito \& Justiça, Porto Alegre, v. 32, n. 1, p. 09-50, jan.jun. 2006.

STRECK, Lenio Luiz. Hermenêutica Jurídica e(m) Crise. 3. ed. Porto Alegre: Livraria do Advogado Editora, 2001. 
ANDRADE, Júlio Thalles de Oliveira. Os direitos fundamentais sociais à luz do princípio da vedação ao retrocesso social. Revista Eletrônica Direito e Política, Programa de Pós-Graduação Stricto Sensu em Ciência Jurídica da UNIVALI, Itajaí, v.11, n.1, $1^{\circ}$ quadrimestre de 2016. Disponível em: www.univali.br/direitoepolitica - ISSN 1980-7791.

Submetido em: Fevereiro/2016

Aprovado em: Abril/2016 